\title{
A SYSTEMATIC REVIEW ON SMART CITY SERVICES AND IOT-BASED TECHNOLOGIES
}

\author{
Firat Bestepe and Sevgi Ozkan Yildirim \\ Middle East Technical University, Turkey
}

\begin{abstract}
Due to the technological developments, Internet of things (IoT) has become a real phenomenon. Accordingly, many IoT-based smart concepts appeared in our daily lives such as smart home, smart healthcare and smart city. There are several factors accelerating or hindering the adoption of such new services and concepts. So, the acceptance of IoT-based smart services is critical and should be analyzed carefully. In this study, we aimed to prepare a proper starting point for future studies on end user acceptance of smart city services and IoT technologies by presenting a comprehensive systematic review of literature. We got 34 articles focusing on the adoption of IoT-based services with a model-based approach among initially resulted 237 papers. Our findings indicate that the adoption of smart services is getting more and more popular in recent years, especially in Asian countries. We also see that most reviewed studies prefer to develop integrated adoption models and deploy the factors of technology acceptance model (TAM). Additionally, our review results show that the researchers studying on this field generally use demographics in adoption models, mostly as control variables. This paper presents valuable findings lightening up the way of researchers who want to develop an adoption model for IoT-based smart services.
\end{abstract}

\section{KEYWORDS}

Internet of Things, Smart Services, User Acceptance, Adoption, Systematic Literature Review

\section{INTRODUCTION}

Cost-effective technologies, broad access to wireless networks and mobility are changing our lives rapidly. Almost all physical objects such as vehicles, home appliances, buildings, embedded with sensors, gain connectivity to collect and exchange data(C.L. Hsu \& Lin 2018). Accordingly, smart healthcare, smart home and smart city concepts are emerged based on solutions with internet of things (IoT) technology. Due to IoT, it is expected to reach 24 billion devices connected by 2020(Gubbi et al. 2013). However, highly digitized structure based on large volumes of digital data due to many physical objects connected bring out many challenging issues such as security, privacy, interoperability, scalability, adaptability, standardization and so on(Atzori, Iera, \& Morabito 2010). These open issues, which are the main barriers to extensive usage of IoT-based smart services, still wait feasible solutions. Besides, IoT based smart concepts cover some other disruptive technologies such as cloud computing and big data. Such a deep change potential of IoT and attached technologies on daily routines would also affect end users' intention to use smart services. So, acceptance of IoT-based services by end users become an issue to be evaluated by IT companies and city administration. The success of investments made to make the cities smarter and improve the quality of life depends on whether or not people adopt these smart services in their daily routines. There are many factors analyzed in the literature accelerating or hindering the adoption of such new technologies and concepts. However, the adoption of smart city services and IoT technologies were not reviewed systematically in the literature much in detail. In this study, we reviewed the academic literature systematically in order to prepare a proper starting point for future studies on end user acceptance of smart city services and IoT technologies. We also aim to fill the gap in information systems (IS) literature on IoT adoption. By this means, the researchers thinking to study adoption of IoT based smart solutions could get our study as a first step and see the potential research fields. 


\section{SEARCH METHODOLOGY}

This literature review study was performed based on 3-stage Kitchenham methodology: planning, conducting and reporting(Kitchenham 2004). In the planning phase, we defined the research criteria and search databases. Then keyword searches were conducted in the specified databases. After the results were managed and assessed, we reported the findings in a systematic manner. The defined search keywords were as follows: ("Smart City" or "Internet of Things") and (Technology or Service) and (Acceptance or Adoption). In order to confine the search scope, only the journal papers written in English and published in between January 2008 - March 2018 in Web of Science, IEEE Xplore, ScienceDirect (Elsevier) and Emerald online libraries were covered. The articles in press, conference proceedings, textbooks, unpublished papers and academic thesis were excluded from the scope of this review. Initially, the search resulted 397 papers. After eliminating irrelevant and duplicated papers, the number of papers reduced to 237.

\section{REVIEW STATISTICS}

72 out of remaining 237 papers are about user acceptance of new technologies, mostly IoT based. 34 papers in this group have a model-based approach for adoption of IoT based technologies and smart services (smart healthcare, smart home/building and smart city). Among these 34 journal papers; 14 studies analyze the adoption of general IoT based services including wearable sensors, RFID (Radio Frequency Identification) sensors and so on. There are 7 papers for each, smart healthcare services and smart home (or building) applications, and they are analyzing adoption issue from end users' perspective. Only 6 out of 34 articles directly study the acceptance and adoption of smart city services with a model-based approach (Figure 1). As seen in Figure 2, the number of academic studies on adoption and acceptance of IoT based technologies and services have been increasing dramatically in last three years (note: just first quarter of 2018 is covered). This indicates that adoption of IoT based smart services is getting more popular rapidly. Especially in Asian countries, there are much more studies on user acceptance matters than other parts of the world (Figure 3).

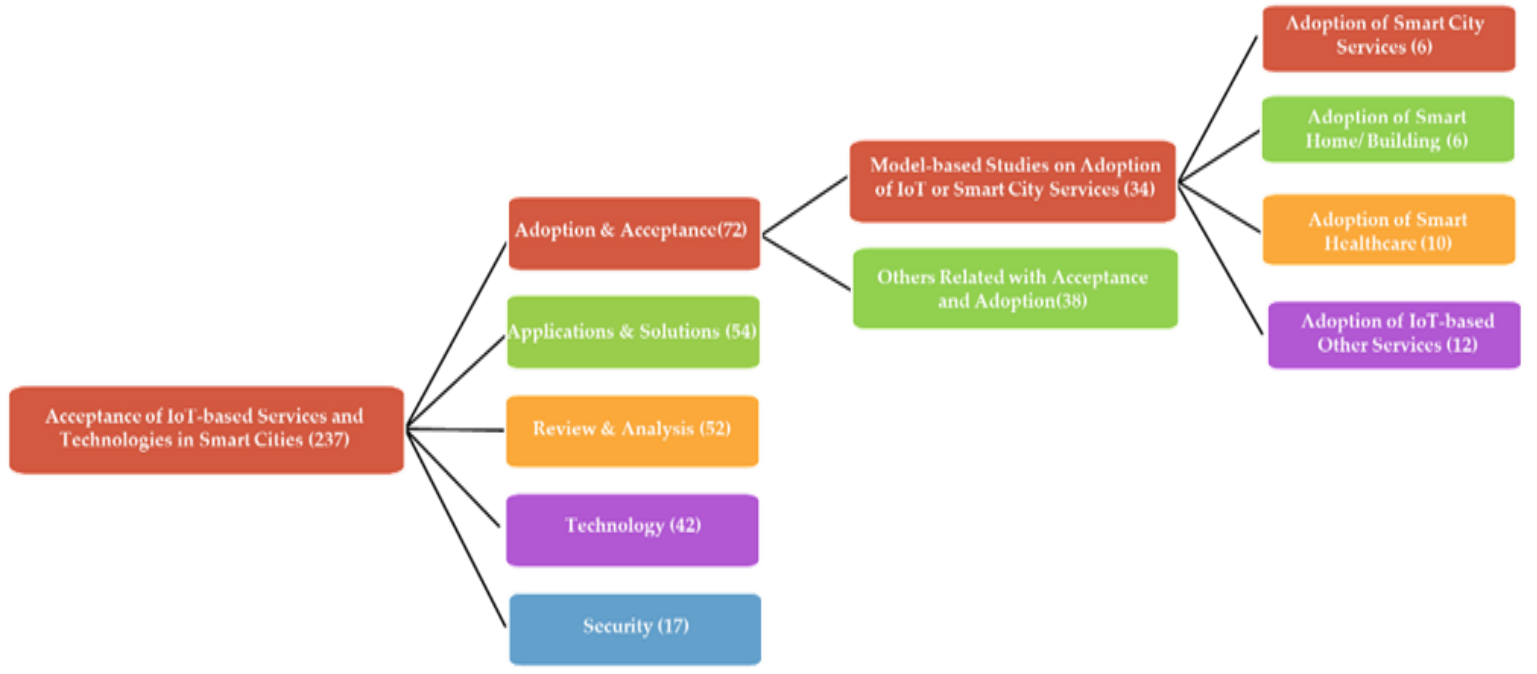

Figure 1. Classification of Reviewed Papers

When looking at the research methodologies, questionnaire is the most preferred survey method in model-based adoption studies (31 out of 34) to get the intentions of users or potential users. Just three of them have conducted expert interview or focus group technique while analyzing end user adoption issue. Most questionnaires (13) are solely online, however, 5 studies preferred to use both online and paper-based surveys. Totally, $58 \%$ of reviewed studies have employed online surveys. Just $16 \%$ of them (5 out of 34) have conducted fully paper-based surveys. In 8 studies, there isn't any specification about survey method. Average number of respondents in surveys is 373 . The maximum and minimum number of sample size are 1091 and 76, respectively. There are several statistical techniques used in the reviewed papers such as 
First-Generation Multiple Regression Analysis, Kruskal-Wallis H Test, Back Propagation Neural Network Analysis and etc. However, most of the researchers (74\% - 23 out of 31 studies) have employed Structural Equation Modelling technique to test the hypothesis and validate the proposed models statistically. Smart PLS is the most preferred statistical tool (29\% - 9 of the studies). Other popular tools are AMOS and LISREL. 11 studies (35\%) do not say anything on statistical tool used.

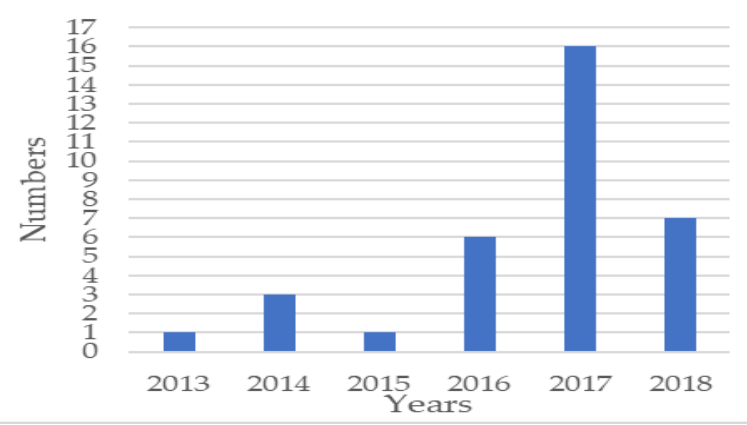

Figure 2. Distribution of Papers Over Years

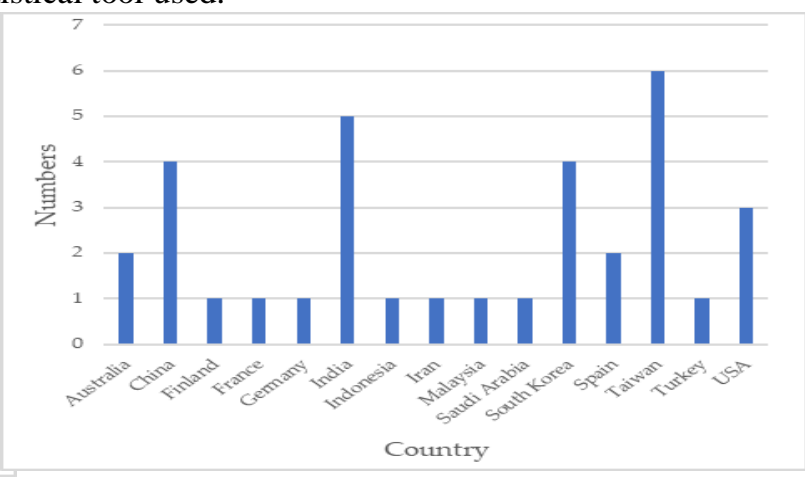

Figure 3. Distribution of Papers by Countries

\section{REVIEW RESULTS}

In 6 out of 34 articles, the researchers have studied the acceptance of smart city services such as smartcards, municipal Wi-Fi, mobile sensing and e-government applications from the citizens' perspective (Yeh 2017; Susanto, Diani, \& Hafidz 2017; Leao \& Izadpahani 2016; Sheshadri Chatterjee \& Arpan Kumar Kar 2017; Gracia, Ariño, \& Rueda 2015; Ylipulli et al. 2014). Smart home or smart building term implies a complete solution based on IoT to monitor, control and manage connected electronic or non-electronic devices used in a home. In this literature review, we get 6 papers studying the acceptance of smart home or smart building applications (Saeidi, Tajfar, \& Vahdat 2017; Y. Kim, Park, \& Choi 2017; E. Park et al. 2017; Dong et al. 2017; Bao et al. 2014; Srikanth Beldona, Zvi Schwartz, \& Xian Zhang 2018). Reduced cost of technology and communication have triggered the digital revolution. Relatedly, by embedding IoT-based technologies into the healthcare systems and applications, smart healthcare phenomenon is emerged. During this literature review, we get 10 papers studying the adoption model of smart healthcare products (Marakhimov \& Joo 2017; Papa et al. 2018; Martínez-Caro et al. 2018; D. Pal et al. 2018; Karahoca, Karahoca, \& Aksöz 2017; Alaiad \& Zhou 2017; Chong et al. 2015; S. Kim \& Kim 2017; Liu, Chen, \& Tzeng 2017; Canhoto \& Arp 2017). Smart solutions implementing automated services under the concept of IoT could provide more efficient business processes and increased quality of life. So, IoT-based smart services and their adoption are critical matters for end user, so as for researchers. The results of our review have yielded 12 papers on end user acceptance of IoT-based services (Hsu \& Lin 2018; Mital et al. 2017; Hsu \& Lin 2016; Gao \& Bai 2014; Tsai et al. 2017; Singh, Gaur, \& Ramakrishnan 2017; Mani \& Chouk 2017; Tu 2018; Yildirim \& Ali-Eldin 2018; Shin 2017; Roy et al. 2018; Hsu \& Yeh 2017). Our review has showed that many different adoption factors are deployed in user acceptance studies according to relevant core technology and preferred model. By comprehensive analysis of each factor deployed in each adoption model reviewed, we have defined adoption factors used in different models but having similar or same meaning. According to our findings, there are 50 different factors used in adoption models of IoT based smart services. The most preferred factors are perceived usefulness (PU) and perceived ease of use (PEOU) which were introduced by Davis (Davis 1989). This is not an unexpected finding because Davis's Technology Acceptance Model (TAM) has a broad usage area in the literature because of its simplicity and relevance for the technology acceptance. Social influence or subjective norm is another commonly used adoption factor which is strongly taken part in the literature with Theory of Reasoned Action (TRA) model (Fishbein \& Ajzen 1975; Ajzen 1991). Interestingly, the privacy concern is the third most preferred factor. When considering the increased security threats and user awareness on privacy risks recently, this finding is quite reasonable. The other common factors are cost, attitude, trust, perceived behavioral control and perceived enjoyment. In most studies, researchers have evaluated the demographics of the respondents, as well (74.2\%). In just 8 of 31 studies (25.8\%), there is no statement about the demographics of the users. The most used ones are gender, age and education. Income and use experience are other commonly preferred demographic features surveyed. 


\section{CONCLUSION}

The smart services based on interconnected devices such as wireless sensors, smart cards and mobile phones allow users to interact with smart environments connected to the internet (i.e. home, office, building, even city). Many daily life activities such as transportation, shopping, education, even healthcare services could become more efficient thanks to the smart services. However, the users should embed these smart services into their daily routines properly and effectively. Therefore, user acceptance of such services and technologies is very critical. For this reason, in this study, we have reviewed the literature on the adoption of IoT based smart services in between 2008 - 2018 (till the end of the first quarter) systematically. We have aimed to present the state of the art and trending research areas for the adoption of IoT based smart services.

The quantitative results of this review show that the number of academic studies on adoption and acceptance of IoT based technologies and services have been increasing dramatically especially in last three years and Asian countries are much more concerned about the technology adoption and user acceptance matters than other parts of the world. The literature on the adoption of smart city services looks a bit poorer than smart home and smart healthcare. However, all these smart concepts are mostly based on IoT technology. So, adoption studies on different smart concepts can easily feed each other. By examining the papers in detail, we have provided the most preferred adoption factors in IoT acceptance literature.

Our study is not a meta-analysis, so we have just reviewed the papers relevant to our search objective and analyzed acceptance factors and demographics used in adoption models. As a limitation, most reviewed studies are examining the intention to use rather than the actual use. In future studies, with the increased usage of IoT-based smart services, it should be useful or even necessary to analyze the actual use of such services. Also, longitudinal studies should be conducted rather than cross-sectional studies in order to understand continuous use of IoT-based smart services properly. Finally, because of our search criteria, we might have missed some valuable studies in the field, as well.

\section{REFERENCES}

Ajzen, I. (1991). The Theory of Planned Behavior. In Organizational Behavior and Human Decision Processes, 179-211.

Alaiad, A., \& Zhou, L. (2017). Patients' Adoption of WSN-Based Smart Home Healthcare Systems: An Integrated Model of Facilitators and Barriers. IEEE Transactions on Professional Communication 60 (1): 4-23.

Atzori, L., Iera, A., \& Morabito, G. (2010). The Internet of Things: A Survey. Computer Networks 54 (15): 2787-2805.

Beldona, S., Schwartz, Z., \& Zhang, X. (2018). Evaluating Hotel Guest Technologies: Does Home Matter? International Journal of Contemporary Hospitality Management, March.

Bao, H., Chong, A.Y.L., Ooi, K.B., \& Lin, B. (2014). Are Chinese Consumers Ready to Adopt Mobile Smart Home? An Empirical Analysis. International Journal of Mobile Communications 12 (5): 496-511.

Canhoto, A.I., \& Arp, S. (2017). Exploring the Factors That Support Adoption and Sustained Use of Health and Fitness Wearables. Journal of Marketing Management 33 (1-2): 32-60.

Chatterjee, S. \& Kar, A.K. (2017). Effects of Successful Adoption of IT Enabled Services in Proposed Smart Cities of India: from User Experience Perspective.” Journal of Science and Technology Policy Management, December.

Chong, A.Y.L., Liu, M.J., Luo, J., \& Keng-Boon, O. (2015). Predicting RFID Adoption in Healthcare Supply Chain from the Perspectives of Users. International Journal of Production Economics 159 (January): 66-75.

Davis, F.D. (1989). Perceived Usefulness, Perceived Ease of Use, and User Acceptance of Information Technology. MIS Quarterly 13 (3): 319-40.

Dong, X., Chang, Y., Wang, Y., \& Yan, J. (2017). Understanding Usage of Internet of Things (IOT) Systems in China Cognitive Experience and Affect Experience as Moderator. Information Technology \& People 30 (1): 117-38.

Fishbein, A. \& Ajzen, I. (1975). Belief, Attitude, Intention and Behavior: An Introduction to Theory and Research. Vol. 27.

Gao, L. \& Bai, X. (2014). Unified Perspective on the Factors Influencing Consumer Acceptance of Internet of Things Technology. Asia Pacific Journal of Marketing and Logistics 26 (2): 211-31.

Gracia, D.B., Ariño, L.V.C., \& Rueda, A.P. (2015). Determinants of Multi-Service Smartcard Success for Smart Cities Development: A Study Based on Citizens' Privacy and Security Perceptions. Government Information Quarterly 32 (2): 154-63. 
Gubbi, J., Buyya, R., Marusic, S., \& Palaniswami, M. (2013). Internet of Things (IoT): A Vision, Architectural Elements, and Future Directions. Future Generation Computer Systems 29 (7): 1645-60.

Hsu, C.W., \& Yeh, C.C. (2017). Understanding the Factors Affecting the Adoption of the Internet of Things. Technology Analysis \& Strategic Management 29 (9): 1089-1102.

Hsu, C.L., \& Lin, J.C.C. (2016). An Empirical Examination of Consumer Adoption of IoT Services: Network Externalities and Concern for Information Privacy Perspectives. Computers in Human Behavior 62 (September): 516-27.

Hsu, C.L., \& Lin, J.C.C. (2018). Exploring Factors Affecting the Adoption of Internet of Things Services. Journal of Computer Information Systems 58 (1): 49-57.

Karahoca, A., Karahoca, D., \& Merve Aksöz. (2017). Examining Intention to Adopt to Internet of Things in Healthcare Technology Products. Kybernetes 47 (4): 742-70.

Kim, S., \& Kim, S. (2017). User Preference for an IoT Healthcare Application for Lifestyle Disease Management. Telecommunications Policy.

Kim, Y., Park, Y., \& Choi, J. (2017). A Study on the Adoption of IoT Smart Home Service: Using Value-Based Adoption Model. Total Quality Management \& Business Excellence 28 (9-10): 1149-65.

Kitchenham, B. (2004). Procedures for Performing Systematic Reviews. 33.

Leao, S., \& Izadpahani, P. (2016). Factors Motivating Citizen Engagement in Mobile Sensing: Insights from a Survey of Non-Participants. Journal of Urban Technology 23 (4): 85-103.

Liu, Y., Chen, Y., \& Tzeng, G.H. (2017). Identification of Key Factors in Consumers' Adoption Behavior of Intelligent Medical Terminals Based on a Hybrid Modified MADM Model for Product Improvement. International Journal of Medical Informatics 105 (September): 68-82.

Mani, Z. \& Chouk, I. (2017). Drivers of Consumers' Resistance to Smart Products. Journal of Marketing Management 33 (1-2): 76-97.

Marakhimov, A. \& Joo, J. (2017). Consumer Adaptation and Infusion of Wearable Devices for Healthcare. Computer in Human Behavior 76 (November): 135-48.

Martínez-Caro, E., Cegarra-Navarro, J.G., García-Pérez, A., \& Fait, M. (2018). Healthcare Service Evolution towards the Internet of Things: An End-User Perspective. Technological Forecasting and Social Change.

Mital, M., Chang,V., Choudhary, P., Papa, A., \& Pani, A.K. (2017). Adoption of Internet of Things in India: A Test of Competing Models Using a SEM Approach. Technological Forecasting and Social Change.

Pal, D., Funilkul, S., Charoenkitkarn, N., \& Kanthamanon, P. (2018). Internet-of-Things and Smart Homes for Elderly Healthcare: An End User Perspective. IEEE Access 6: 10483-96.

Papa, A., Mital, M., Pisano, P., \& Giudice, M.D. (2018). E-Health and Wellbeing Monitoring Using Smart Healthcare Devices: An Empirical Investigation." Technological Forecasting and Social Change.

Park, E., Cho, Y., Han, J., \& Kwon, S. J. (2017). Comprehensive Approaches to User Acceptance of Internet of Things in a Smart Home Environment. IEEE Internet of Things Journal 4 (6): 2342-50.

Roy, S.K., Balaji, M.S., Quazi, A., \& Quaddus, M. (2018). Predictors of Customer Acceptance of and Resistance to Smart Technologies in the Retail Sector. Journal of Retailing and Consumer Services 42 (May): 147-60.

Saeidi, M., Tajfar, A.H., and Vahdat, D. (2017). Assessing of the Effective Factors in the Acceptance of Internet of Things Technology in Smart Buildings Journal of Fundamental and Applied Sciences 9 (1, SI): 1102-16.

Shin, D.H. (2017). Conceptualizing and Measuring Quality of Experience of the Internet of Things: Exploring How Quality is Perceived by Users. Information \& Management 54 (8): 998-1011.

Singh, G., Gaur, L., \& Ramakrishnan, R. (2017). Internet of Things - Technology Adoption Model in India. Pertanika Journal of Science and Technology 25 (3): 835-46.

Susanto, T.D., Diani, M.M., \& Hafidz, I. (2017). User Acceptance of E-Government Citizen Report System (a Case Study of City113 App). Procedia Computer Science, 124 (January): 560-68.

Tsai, Y.T., Wang, S.C., Yan, K.Q., \& Chang, C.M. (2017). Precise Positioning of Marketing and Behavior Intentions of Location-Based Mobile Commerce in the Internet of Things. Symmetry-Basel 9 (8).

Tu, M. (2018). An Exploratory Study of Internet of Things (IoT) Adoption Intention in Logistics and Supply Chain Management: A Mixed Research Approach. The International Journal of Logistics Management 29 (1): 131-51.

Yeh, H. (2017). The Effects of Successful ICT-Based Smart City Services: From Citizens' Perspectives. Government Information Quarterly 34 (3): 556-65.

Yildirim, H. \& Ali-Eldin, A.M.T. (2018). A Model for Predicting User Intention to Use Wearable IoT Devices at the Workplace. Journal of King Saud University - Computer and Information Sciences.

Ylipulli, J., Suopajarvi, T., Ojala, T., Kostakos, V., \& Kukka, H. (2014). Municipal WiFi and Interactive Displays: Appropriation of New Technologies in Public Urban Spaces." Technological Forecasting and Social Change 89 (November): 145-60. 